\title{
Nosocomial Infection: Causes Treatment and Management
}

\author{
Safila Naveed*, Aisha Sana, Halima Sadia, Fatima Qamar and Nida Aziz \\ Faculty of Pharmacy, Jinnah University for Women, Pakistan
}

*Corresponding author: Safila Naveed, Faculty of Pharmacy, Jinnah University for Women, Pakistan.

To Cite This Article: Safila Naveed. Nosocomial Infection: Causes Treatment and Management. Am J Biomed Sci \& Res. 2019 - 5(3). AJBSR. MS.ID.000901. DOI: 10.34297/AJBSR.2019.05.000901.

Received: 鮆September 05, 2019; Published: 眥September 17, 2019

\section{Hospital Acquired Infection}

Hospital acquired infection is also known as nosocomial infection or health care associated infection it is occur when patient admitted in hospital but with other type of infection or at the time of admission in hospital infection is not usually present in patient or it is usually occur in hospital during medical care of patient and this is the basic reason of death in hospitalized patient it can affect the patient emotional stress, decease the quality of life, and increase the patient stay in hospital it can also transmitted to the community when the patient discharge [1].

\section{Causes of Hospital Acquired Infection}

\section{Microbes}

During medical care in hospital patient are exposed to a verity of microorganism which can cause much clinical disorder it may cause by microorganism present in other patient admitted in hospital known as cross infection.

\section{Patient susceptibility}

It includes
a) Age of the patient
b) Immune system
c) Transmission of disease from staff and another patient among the patient

d) Any type of comorbid disease

e) Diagnostic procedures

f) Using contaminated object inserted directly into the tissue [2]

\section{Causative Agent}

The most common causative agent of nosocomial infection is Staphylococcus aureus, E coli, pseudomonas areginosa and it is not just link to bacteria it is also cause by fungi as well by virus. Infection usually occurs up to in 48 hours when admitted in hospital or occur within 3 days after discharge they can transmit through hand, through oral, parentral, aerial and vector borne (Figure 1).

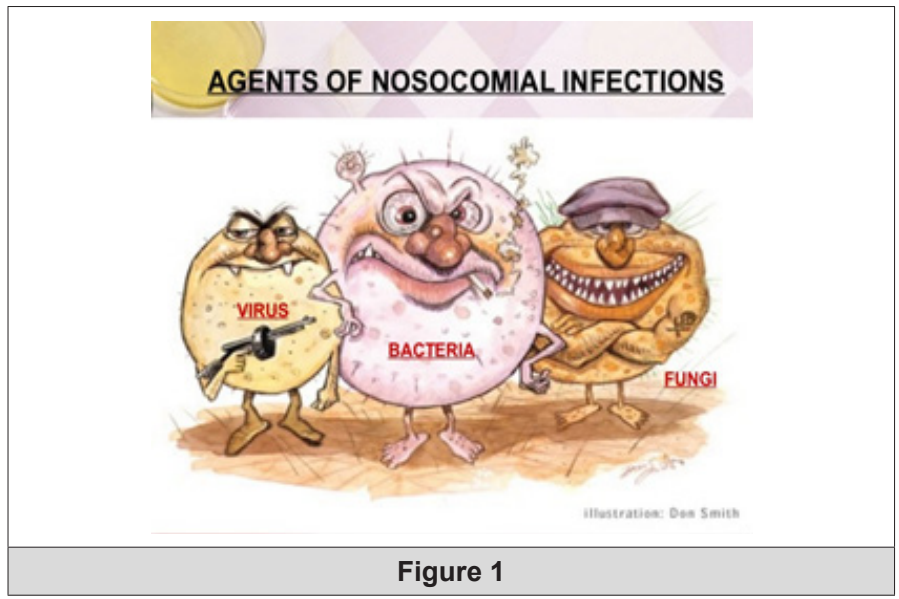

Types of Nosocomial Infection

The most common nosocomial infection or hospital acquired infection are include (Figure 2):

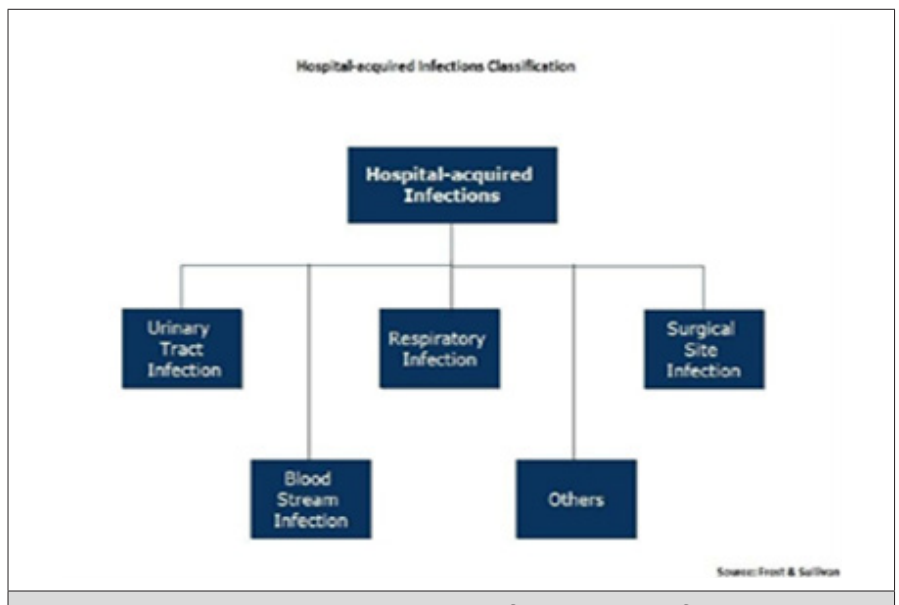

Figure 2: Hospital-acquired Infections classification

A. Blood stream infection

B. Urinary tract infection 
C. Infection of surgical wound

D. Pneumonia (ventilator associated) [3]

A. Blood stream infection

It is called center line associated blood stream infection It is use for IV medication, treatment there risk increase when they are placed in center line and its prolong use can cause blood stream infection as germs can enter into the blood and to prevents this different guideline are provided that is before insertion of catheter should educate the patient and to avoid catheter to place in femoral vein do not use catheter for prolong period of time [4].

\section{B. Urinary tract infection}

The most common type of nosocomial infection is catheter associated urinary tract infection which is caused by the patient native micro flora about $75 \%$ patient are affected by this its occur due to prolong use of catheter which is inserted in the bladder for the urinary drainage so to prevent this catheter can be use under the supervision of expert and can be use when it is necessary and should be remove as soon as possible because it may cause some serious consequences like prostatitis, meningitis, cystitis etc., [4].

\section{Surgical site infection}

This is the 2 most common type of infection occur in hospital caused by staphylococcus aureus it can occur usually in that type of part where surgery occur and sometimes it involves the skin only. It can develop usually after 30 days of operation it includes superficial incision in which pus can produce from the wound area in deep incision SSI pus can be produce from the wound when it reopens. It can be treated by taking antibiotic, if complications occur then sometime another surgery is also required, and it can also be prevented by maintaining hygiene condition [5].

\section{Pneumonia (Ventilator Associated)}

It is usually occur when patient is on ventilator which provide oxygen to them through a tube which is attach to the mouth and nose of the patient if the germs can enter into the mouth through this tube then this infection tale place which is usually occur in 9 to $27 \%$ of patient .It is usually occur by both gram negative bacteria like Pseudomonas aregunosa, E.coli, staphylococcus aureus. It is usually diagnosis when the patient can develop infiltrate on chest radiograph, leukocytosis, and produce purulent tracheobronchial secretions [6].

\section{Treatment and Management}

There are various types of treatment present, but it depends on the severity of the infection and the causative agent is the responsibility of the medical care center to prevent hospital acquired infection by following different guideline and these are (Figure 3):

a) Observe the patient in ICU or any other ward that if the patient need isolation or not to stop the transmission of disease

b) Hygiene condition should be maintaining by washing hands before and after touching the patients

c) Any type of object insertion in body should be in aseptic condition

d) Infection control program should be developed

e) Antimicrobial use should be appropriate

f) Air borne precaution should provide

g) Use aseptic catheter for UTI infection and the urinary bag never have contact with floor

h) Whenever possible use noninvasive ventilator

i) Ventilator circuit routinely changing is not required

j) For the insertion of catheter Prefer the upper extremity

k) Wash or clean your skin with chlorhexidine

l) Should frequently change needleless connecters [7-10].

\section{Isolation of infectious patient}

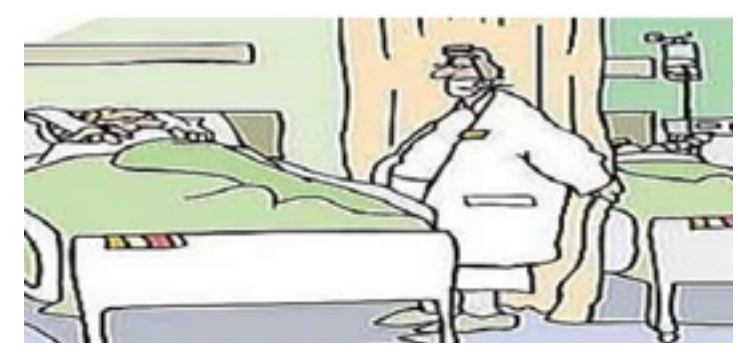

Figure 3

\section{References}

1. Hoi AB, H Richet (1985) A prospective study of hospital-acquired infection in 2330 cardiovascular surgery patients. Journal of Hospital Infection 6(3): 333-341.

2. Naveed S, Ghulam Sarwar, Raazia Hassan, Sehrish Khan, Saima Afzal, et al., Irrational Use of Cephalosporin and Quinolones in Public and Private Sectors Hospitals of Karachi. J App Pharm 6(3): 252-260.

3. Tariq A, Ali H, Zafar F, Sial AA, Hameed K, et al., (2017) A systemic review on surgical site infections: Classification, risk factors, treatment complexities, economical and clinical scenarios. J Bioequiv Availab 9: 336-340.

4. Siddiqui MS, Saeed A, Nawaz A, Naveed S, Usmanghani K (2016) The effects of new polyherbal Unani formulation AJMAL06 on serum creatinine level in chronic renal failure. Pak J Pharm Sci 29(2 Suppl): 657-661.

5. Naveed S, Qamar F, Maqsood A, Ayub A, Kauser H, et al., (2015) Prevalence and consequences of misuse of antibiotics, survey-based study in Karachi. Journal of Bioequivalence \& Bioavailability 7(5): 202-204.

6. Gurgel A, Jackeline G da Silva, Ana RS Grangeiro, Haroudo S Xavier, Rinalda AG Oliveira, et al., (2009) Antibacterial effects of Plectranthus amboinicus (Lour) spreng (Lamiaceae) in methicillin resistant Staphylococcus aureus (MRSA). Latin American Journal of Pharmacy 28(3): 460-464. 
7. Willcox MD (2011) Review of resistance of ocular isolates of Pseudomo nas aeruginosa and staphylococci from keratitis to ciprofloxacin, gentamicin and cephalosporins. Clinical and Experimental Optometry 94(2): 161-168.

8. Anacona JR, L Brito (2011) In vitro cytotoxicity and antibacterial activities of cephalosporin Tin (II) complexes. Latin American Journal of Pharmacy p. 30.
9. Naqvi GR, Baqir S Naqvi, Harris M Shoaib, Huma Ali, Farya Zafaret, al., (2018) Pharmaceutical Surveillance Study of Moxifloxacin Formulations: Therapeutic Perspective in Terms of Quality and Efficacy. Lat Am J Pharm 37(6): 1104-1114.

10. Mahesh N, AA Hajare (2010) Ion activated in situ gel system for ophthalmic delivery of Moxifloxacin hydrochloride. Latin American Journal of Pharmacy 29(6): 876-882. 